\title{
Impact and Predictors of Prolonged Chest Tube Duration in Mechanically Ventilated Patients with Acquired Pneumothorax
}

\author{
Jiann-Hwa Kao MD, Hsin-Kuo Kao MD, Yen-Wen Chen MD, \\ Wen-Kuang Yu MD, Sheng-Wei Pan MD, Jia-Horng Wang MD, \\ Te-Cheng Lien MD, Li-Ing Ho MD, and Yu Ru Kou PhD
}

\begin{abstract}
BACKGROUND: Prolonged chest tube duration is less well studied in patients who are supported by mechanical ventilation and have acquired pneumothorax. We investigated the impact of prolonged chest tube duration on patient outcomes and the risk factors associated with prolonged chest tube duration. METHODS: This retrospective observational study included 106 ventilated subjects who had been treated with thoracostomy for pneumothorax between May 2004 and December 2011. We analyzed 61 subjects and 63 events. The subjects were divided into a prolonged chest tube duration group ( $>18 \mathrm{~d}$ ) and a non-prolonged group ( $\leq 18 \mathrm{~d})$. RESULTS: Subjects with prolonged chest tube duration had significantly higher ICU mortality $(P=.006)$, longer ICU stay $(P=.001)$, longer hospitalization $(P=\mathbf{. 0 0 4})$, longer mechanical ventilation after development of pneumothorax $(P=.003)$, higher maximum peak inspiratory pressure $(P=.03)$, and a higher rate of surgical emphysema $(P=.009)$. High peak inspiratory pressure and surgical emphysema remained independent predictors of prolonged chest tube duration after multivariate logistic regression analysis. The probability of chest tube removal within 28 days was significantly lower in subjects with both high peak inspiratory pressure and surgical emphysema, compared to subjects without any risk factors (log rank $P=.001)$. CONCLUSIONS: High peak inspiratory pressure and surgical emphysema are independent predictors of prolonged chest tube duration and negatively impact clinical outcomes in this patient group. These findings may provide information for better chest tube management. Key words: pneumothorax; chest tube; thoracostomy; mechanical ventilation; subcutaneous emphysema; peak inspiratory pressure. [Respir Care 2013;58(12):2093-2100. (C) 2013 Daedalus Enterprises]
\end{abstract}

\section{Introduction}

Pneumothorax occurs in $4-15 \%$ of patients receiving mechanical ventilation, and is considered a medical emergency that requires prompt recognition and careful management. ${ }^{1,2}$ Thoracostomy with chest tube placement to relieve the life-threatening pneumothorax is mandatory for

\footnotetext{
The authors are affiliated with the Department of Respiratory Therapy, Taipei Veterans General Hospital, Taipei, Taiwan, with the exception of $\mathrm{Yu} \mathrm{Ru}$ Kou PhD, who is affiliated with the Institute of Physiology and the Institute of Emergency and Critical Care Medicine, School of Medicine, National Yang-Ming University, Taipei, Taiwan. Dr Li-Ing Ho is the co-corresponding author.
}

This study was supported by grant NSC 101-2320-B-010-042-MY3 from the National Science Council of the Republic of China. The authors have disclosed no conflicts of interest. these patients. ${ }^{1,2}$ Complications of tube thoracostomy include infection, tube malpositioning, laceration, and hemothorax, all of which may worsen outcome. ${ }^{3-9}$ Several studies have compared the safety and efficacy of different chest tube sizes ${ }^{3,10-12}$ and various methods of chest tube removal. ${ }^{13,14}$ Chest tube duration would seem to be an important management issue that might impact outcome, but there is a paucity of data on the impact of and risk factors affecting prolonged chest tube duration in patients with pneumothorax.

\footnotetext{
Correspondence: Yu Ru Kou PhD, Institute of Physiology, School of Medicine, National Yang-Ming University, Taipei, 112 Taiwan. E-mail: yrkou@ym.edu.tw.
}

DOI: $10.4187 /$ respcare. 02273 
The objectives of this study were to examine the impact of prolonged chest tube duration on outcomes in mechanically ventilated patients with acquired pneumothorax, and to identify the risk factors associated with prolonged chest tube duration in these patients. There is no consensus on what constitutes "prolonged" chest tube duration; we defined it as $>18$ days, based on the median chest tube duration among the subjects in this study. Various comparisons were then performed of the prolonged group versus the non-prolonged group.

\section{Methods}

\section{Design, Setting, and Subjects}

This retrospective study was conducted in a 35-bed ICU at Taipei Veterans General Hospital, a 3,000-bed tertiary medical center. The study was registered with our institutional ethical review board (study 2012-03-007AC). The requirement for informed consent was waived, according to our institutional guidelines. Among the patients admitted to the ICU between May 2004 and December 2011, we identified those who had pneumothorax during mechanical ventilation, by searching for the International Classification of Diseases codes associated with pneumothorax (512.8) and respiratory failure (518.81) in the hospital's electronic database. The inclusion criteria were: pneumothorax developed after initiation of mechanical ventilation; and pneumothorax treated with tube thoracostomy using 28 French chest tube and a suction pressure of $10-$ $20 \mathrm{~cm} \mathrm{H}_{2} \mathrm{O}$. The exclusion criteria were: chest tube duration could not be determined exactly; conditions (eg, empyema and hemothorax) requiring chest tube placement that may confound data collected during the subsequent development of pneumothorax; and transferred out of the ICU against the advice of the attending physician after the legal process of the request from the patient's family.

Since there is no consensus on the definition of "prolonged" chest tube duration, we calculated the median chest tube duration among the subjects who successfully had their chest tubes removed during hospitalization, and divided the subjects into a prolonged chest tube duration group and a non-prolonged group, according to chest tube duration greater and not greater than the median value. Subjects who died before the median chest tube duration without chest tube removal were excluded because chest tube duration could not be evaluated.

\section{Data Collection}

Information was collected by careful chart review, using a data sheet specifically designed for this study. The hospital medical records, chest x-rays, and computed tomograms (CT) were reviewed. The following characteristics

\section{QUICK LOOK}

\section{Current knowledge}

Pneumothorax is a sudden and life-threatening complication of mechanical ventilation, and requires prompt placement of a thoracostomy tube. Tube size, method of placement, and method of removal all impact the chest tube duration required.

\section{What this paper contributes to our knowledge}

Prolonged chest tube duration in mechanically ventilated patients with iatrogenic pneumothorax was associated with higher mortality, longer duration of mechanical ventilation, and longer ICU and hospital stay. Surgical emphysema and a high peak inspiratory pressure within 24 hours after thoracostomy were independent predictors of prolonged chest tube duration.

were collected: age, sex, smoking status, comorbidities, cause requiring initiation of mechanical ventilation, Acute Physiology and Chronic Health Evaluation II score on ICU admission, and $\mathrm{P}_{\mathrm{OO}_{2}} / \mathrm{F}_{\mathrm{IO}_{2}}$ on ICU admission. When pneumothorax occurred, the associated manifestations were also recorded, including location of pneumothorax; presence of concurrent septic shock; initial presentation (as either tension pneumothorax, procedure-related pneumothorax, or both); number of chest tubes; frequency of chest CT; surgical interventions; ventilator settings (including maximum tidal volume, minute ventilation, breathing frequency, peak inspiratory pressure [PIP], and PEEP during the 24 hours after thoracostomy); complications of thoracostomy (including empyema, surgical emphysema, and hemothorax); chest tube duration; time to readiness for weaning; time to disconnection from mechanical ventilation; weaning outcome; ICU mortality; and hospital mortality.

\section{Definitions}

The diagnosis of pneumothorax was based on the presence of an abnormal collection of air in the pleural space on an X-ray or CT, before or after chest tube placement. If invasive procedures (eg, thoracocentesis, pericardiocentesis, central venous catheterization, pulmonary artery catheterization, or bronchoscopy) had been performed within 24 hours before a pneumothorax on the same side, the pneumothorax was considered procedure-related. ${ }^{15}$ It was considered a tension pneumothorax if there was an opposite mediastinal shift on x-ray and hemodynamic compromise. ${ }^{15}$ Surgical emphysema was defined as subcutaneous emphysema following chest tube placement. ${ }^{16}$ Empyema was defined as a pleural effusion culture that 
revealed bacterial growth, or if gross pus was drained.Hemothorax was defined as bloody pleural effusion with a hematocrit level more than half of the hematocrit level in the blood. Chest tubes were removed when agreed upon by the surgeon and attending physician if lung expansion on chest x-ray and no leakage of air was observed in the underwater-sealed bottle for 2 days. ${ }^{17}$ Septic shock was defined as systemic inflammatory response syndrome $(\geq 2$ of the following conditions: temperature $>38.5^{\circ} \mathrm{C}$ or $<35.0^{\circ} \mathrm{C}$, heart rate $>90$ beats $/ \mathrm{min}$, breathing frequency $>20$ breaths/min or $\mathrm{P}_{\mathrm{aCO}}<32 \mathrm{~mm} \mathrm{Hg}$, and white blood cell count of $>12,000$ cells $/ \mathrm{mL},<4,000$ cells $/ \mathrm{mL}$, or $>10 \%$ band forms) with shock (arterial systolic blood pressure $<90 \mathrm{~mm} \mathrm{Hg}$, or $40 \mathrm{~mm} \mathrm{Hg}$ less than the subject's normal blood pressure) in response to documented infection.

Ready-for-weaning was defined as meeting the following criteria: recovery from an acute condition causing acute respiratory failure; $\mathrm{P}_{\mathrm{aO}_{2}} / \mathrm{F}_{\mathrm{IO}_{2}}>200 \mathrm{~mm} \mathrm{Hg}$; PEEP $\leq 8 \mathrm{~cm} \mathrm{H} \mathrm{H}_{2} \mathrm{O}$; breathing frequency $<35$ breaths/ min; tidal volume $>5 \mathrm{~mL} / \mathrm{kg}$, minute ventilation $<10 \mathrm{~L} /$ min; stable hemodynamic status without inotropic agents or vasopressors; temperature $<38^{\circ} \mathrm{C}$; and adequate cough reflex and consciousness. Successful weaning from mechanical ventilation was defined as disconnection of invasive ventilation for at least 48 hours.

\section{Statistical Analysis}

We analyzed the differences between subjects with prolonged versus non-prolonged chest tube duration. Categorical data were compared using the chi-square test, and continuous variables were compared using the Student $t$ test or Mann-Whitney U test when the distributions were either normal or not normal, respectively. We identified independent risk factors via multivariate logistic regression. Variables with a $P$ value $<.20$ in the univariate analysis were considered for inclusion in the multivariate model. The multivariate model was also adjusted for confounding factors, including age, sex, smoking status, Acute Physiology and Chronic Health Evaluation II score, and $\mathrm{P}_{\mathrm{aO}} / \mathrm{F}_{\mathrm{IO}_{2}}$. We used receiver operating characteristic curve analysis to determine the optimal cutoff point that allowed the creation of dichotomous variables. The probability of chest tube removal was calculated with the Kaplan-Meier method and the log-rank test. Two-sided tests with a $P$ value of $<.05$ were considered significant. Statistics software (SPSS 19, SPSS, Chicago, Illinois) was used for data analysis.

\section{Results}

\section{Characteristics of the Study Subjects}

One hundred six subjects had both pneumothorax and respiratory failure during the study period (Fig. 1). Eight

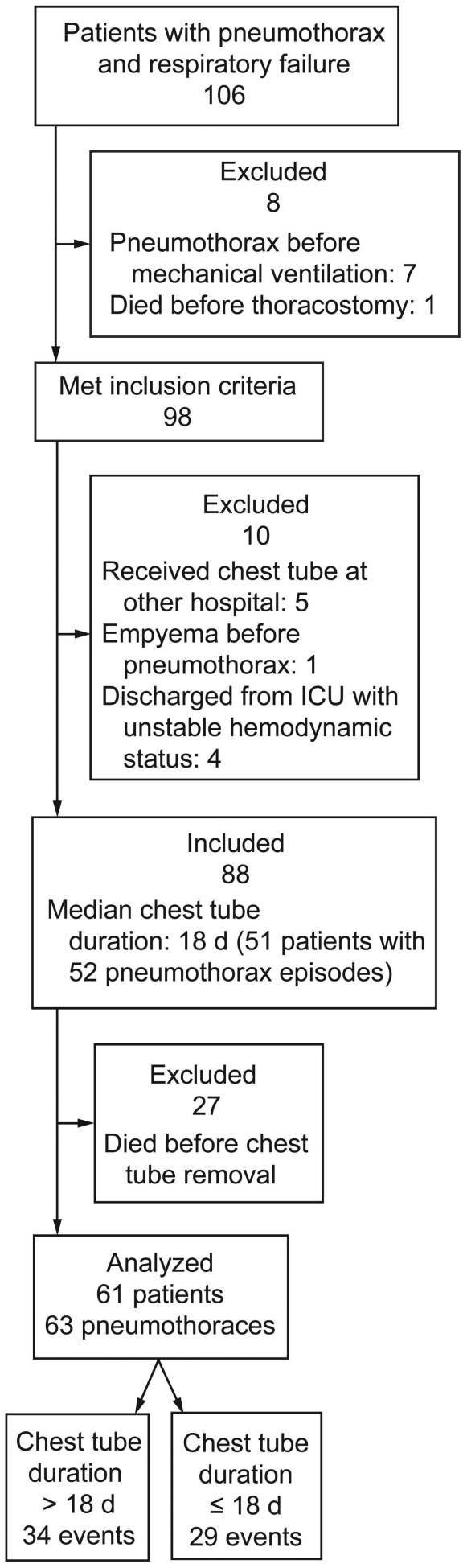

Fig. 1. Flow chart. Median chest tube duration was calculated from 52 pneumothorax episodes in 51 subjects who had successful chest tube removal.

patients were not eligible for inclusion, and 10 were excluded (5 received thoracostomy outside of our hospital, 
Table 1. Baseline Characteristics of the Study Subjects

\begin{tabular}{|c|c|c|c|c|}
\hline & $\begin{array}{l}\text { All } \\
\text { Subjects } \\
n=63^{*}\end{array}$ & $\begin{array}{l}\text { Prolonged } \\
\text { Chest Tube } \\
\text { Duration } \\
n=34\end{array}$ & $\begin{array}{l}\text { Non-prolonged } \\
\text { Chest Tube } \\
\text { Duration } \\
n=29\end{array}$ & $P$ \\
\hline Age, mean $\pm \mathrm{SD}$ y & $78.2 \pm 12.3$ & $76.7 \pm 13.8$ & $80.0 \pm 10.3$ & .29 \\
\hline Male/female, no. & $57 / 6$ & $31 / 3$ & $26 / 3$ & $>.99$ \\
\hline Smoker, no. (\%) & $36(57.1)$ & $23(67.6)$ & $13(44.8)$ & .08 \\
\hline \multicolumn{5}{|l|}{ Comorbidities, no. (\%) } \\
\hline COPD & $41(65.1)$ & $23(67.6)$ & $18(62.1)$ & .79 \\
\hline Interstitial lung disease & $2(3.2)$ & $2(5.9)$ & $0(0)$ & .49 \\
\hline Heart failure & $16(25.4)$ & $11(32.4)$ & $5(17.2)$ & .24 \\
\hline Diabetes mellitus & $15(23.8)$ & $9(26.5)$ & $6(20.7)$ & .76 \\
\hline End-stage renal disease & $2(3.2)$ & $1(2.9)$ & $1(3.4)$ & $>.99$ \\
\hline Neurological disease & $29(46.0)$ & $14(41.2)$ & $15(51.7)$ & .45 \\
\hline Malignancy & $10(15.9)$ & 7 (20.6) & $3(10.3)$ & .31 \\
\hline \multicolumn{5}{|l|}{ Reason for mechanical ventilation } \\
\hline COPD & $29(46.0)$ & $16(47.1)$ & $13(44.8)$ & $>.99$ \\
\hline Post-surgical & $2(3.2)$ & $0(0)$ & $2(6.9)$ & .20 \\
\hline Pneumonia & $24(38.1)$ & $12(35.3)$ & $12(41.4)$ & .79 \\
\hline Pulmonary edema & $2(3.2)$ & $2(5.9)$ & $0(0)$ & .49 \\
\hline ARDS & $1(1.6)$ & $1(2.9)$ & $0(0)$ & $>.99$ \\
\hline Airway protection & $3(4.8)$ & $2(5.9)$ & $1(3.4)$ & $>.99$ \\
\hline Other $\dagger$ & $2(3.2)$ & $1(2.9)$ & $1(3.4)$ & $>.99$ \\
\hline \multicolumn{5}{|l|}{ On ICU admission } \\
\hline APACHE II score, mean \pm SD & $18.7 \pm 6.1$ & $19.3 \pm 6.7$ & $18.1 \pm 5.4$ & .45 \\
\hline $\mathrm{P}_{\mathrm{aO}_{2}} / \mathrm{F}_{\mathrm{IO}_{2}}$, mean $\pm \mathrm{SD} \mathrm{mm} \mathrm{Hg}$ & $292.5 \pm 136.9$ & $288.7 \pm 149.6$ & $297.1 \pm 123.0$ & .81 \\
\hline Oxygenation index, mean $\pm \mathrm{SD} \ddagger$ & $4.4 \pm 3.3$ & $4.6 \pm 4.1$ & $4.2 \pm 2.4$ & .48 \\
\hline \multicolumn{5}{|c|}{$\begin{array}{l}\text { * } 63 \text { episodes in } 61 \text { subjects. } \\
\dagger \text { One subject had asthma, and the other had obesity hypoventilation. } \\
\text { † No data obtained for } 7 \text { subjects, so prolonged } n=29 \text { and non-prolonged } n=27 \text {. } \\
\text { APACHE = Acute Physiology and Chronic Health Evaluation }\end{array}$} \\
\hline
\end{tabular}

Table 2. Outcomes of the Study Subjects With and Without a Prolonged Chest Tube Duration

\begin{tabular}{|c|c|c|c|c|}
\hline & $\begin{array}{c}\text { All } \\
\text { Subjects } \\
n=63 *\end{array}$ & $\begin{array}{c}\text { Prolonged } \\
\text { Chest Tube } \\
\text { Duration } \\
n=34\end{array}$ & $\begin{array}{c}\text { Non-prolonged } \\
\text { Chest Tube } \\
\text { Duration } \\
n=29\end{array}$ & $P$ \\
\hline Chest tube duration, $\mathrm{d}$ & $27.8 \pm 24.6$ & $41.7 \pm 26.0$ & $11.6 \pm 5.7$ & .001 \\
\hline Duration of mechanical ventilation, $\mathrm{d}$ & $47.1 \pm 41.0$ & $53.5 \pm 37.0$ & $39.5 \pm 44.7$ & .17 \\
\hline From mechanical ventilation to pneumothorax, $\mathrm{d}$ & $21.0 \pm 33.2$ & $18.1 \pm 19.0$ & $24.3 \pm 44.6$ & .46 \\
\hline Ready for weaning, no. (\%) & $52(82.5)$ & $27(79.4)$ & $25(86.2)$ & .52 \\
\hline From pneumothorax to ready for weaning $(n=52)$, d & $6.9 \pm 7.0$ & $8.6 \pm 8.1$ & $5.2 \pm 5.1$ & .07 \\
\hline $\begin{array}{l}\text { From pneumothorax to disconnection of mechanical } \\
\text { ventilation, } d\end{array}$ & $26.1 \pm 27.2$ & $35.4 \pm 32.3$ & $15.2 \pm 13.5$ & .003 \\
\hline Successful weaning, no. (\%) & $30(47.6)$ & $14(41.2)$ & $16(55.2)$ & .31 \\
\hline ICU stay, d & $35.9 \pm 18.8$ & $41.3 \pm 17.7$ & $29.6 \pm 18.3$ & .01 \\
\hline From ICU admission to pneumothorax, $\mathrm{d}$ & $8.3 \pm 15.0$ & $7.3 \pm 14.3$ & $9.4 \pm 16.1$ & .59 \\
\hline From pneumothorax to discharge, $\mathrm{d}$ & $27.6 \pm 15: 9$ & $34.0 \pm 17.7$ & $20.2 \pm 9.1$ & .001 \\
\hline Hospital stay, d & $85.9 \pm 118.6$ & $95.5 \pm 99.3$ & $74.6 \pm 138.8$ & .01 \\
\hline From admission to pneumothorax, $\mathrm{d}$ & $36.1 \pm 106.2$ & $32.8 \pm 83.0$ & $40.0 \pm 129.7$ & $>.99$ \\
\hline From pneumothorax to discharge, $\mathrm{d}$ & $49.8 \pm 38.4$ & $62.7 \pm 44.8$ & $34.6 \pm 21.7$ & .004 \\
\hline ICU mortality, no. (\%) & $15(23.8)$ & $13(38.2)$ & $2(6.9)$ & .006 \\
\hline Hospital mortality, no. (\%) & $24(38.1)$ & $17(50)$ & $7(24.1)$ & .04 \\
\hline
\end{tabular}


Table 3. Manifestations and Management of Pneumothorax Among Subjects With and Without Prolonged Chest Tube Duration

\begin{tabular}{|c|c|c|c|c|}
\hline & $\begin{array}{c}\text { All } \\
\text { Subjects } \\
n=63^{*}\end{array}$ & $\begin{array}{l}\text { Prolonged } \\
\text { Chest Tube } \\
\text { Duration } \\
n=34\end{array}$ & $\begin{array}{l}\text { Non-prolonged } \\
\text { Chest Tube } \\
\text { Duration } \\
n=29\end{array}$ & $P$ \\
\hline Bilateral pneumothorax, no. (\%) & $5(7.9)$ & $4(11.8)$ & $1(3.4)$ & .36 \\
\hline Procedure-related pneumothorax, no. (\%) & $19(30.2)$ & $10(29.4)$ & $9(31.0)$ & $>.99$ \\
\hline Tension pneumothorax, no. (\%) & $4(6.3)$ & $3(8.8)$ & $1(3.4)$ & .61 \\
\hline Concurrent septic shock, no. (\%) & $5(7.9)$ & $3(8.8)$ & $2(6.9)$ & $>.99$ \\
\hline Thoracotomy, no. (\%) & $2(3.2)$ & $2(5.9)$ & $0(0)$ & .49 \\
\hline Chest CT, no. (\%) & $34(54.0)$ & $23(67.6)$ & $11(37.9)$ & .02 \\
\hline Number of CTs, mean $\pm \mathrm{SD}$ & $0.8 \pm 1.0$ & $1.2 \pm 1.2$ & $0.4 \pm 0.6$ & .003 \\
\hline Number of chest tubes, mean \pm SD & $1.4 \pm 0.7$ & $1.7 \pm 0.8$ & $1.2 \pm 0.5$ & .005 \\
\hline \multicolumn{5}{|l|}{$\begin{array}{l}\text { Mechanical ventilation settings within } 24 \mathrm{~h} \text { of } \\
\text { thoracostomy }(n=56) \text {, mean } \pm \mathrm{SD}\end{array}$} \\
\hline Maximum PEEP, $\mathrm{cm} \mathrm{H}_{2} \mathrm{O}$ & $2.9 \pm 2.7$ & $2.8 \pm 2.9$ & $2.9 \pm 2.5$ & .78 \\
\hline Maximum PIP, $\mathrm{cm} \mathrm{H}_{2} \mathrm{O}$ & $25.8 \pm 6.0$ & $27.6 \pm 6.2$ & $24.0 \pm 5.2$ & .03 \\
\hline Maximum $\dot{\mathrm{V}}_{\mathrm{E}}, \mathrm{L} / \mathrm{min}$ & $11.2 \pm 3.3$ & $11.9 \pm 4.1$ & $10.4 \pm 2.2$ & .13 \\
\hline Maximum $\mathrm{V}_{\mathrm{T}}, \mathrm{mL}$ & $616.5 \pm 133.3$ & $612.1 \pm 131.2$ & $621.2 \pm 138.2$ & .90 \\
\hline Maximum breathing frequency, breaths/min & $20.1 \pm 7.3$ & $21.8 \pm 9.0$ & $18.3 \pm 4.5$ & .08 \\
\hline \multicolumn{5}{|l|}{ Complications } \\
\hline Surgical emphysema, no. (\%) & $38(60.3)$ & $26(76.5)$ & $12(41.4)$ & .009 \\
\hline Time to surgical emphysema, mean $\pm \mathrm{SD} d$ & $1.2 \pm 3.0$ & $1.5 \pm 3.5$ & $0.5 \pm 0.8$ & .66 \\
\hline Empyema, no. (\%) & $21(33.3)$ & $17(50)$ & $4(13.8)$ & .002 \\
\hline Time to empyema, mean \pm SD d & $13.0 \pm 13.0$ & $14.3 \pm 13.2$ & $7.5 \pm 11.9$ & .38 \\
\hline $\begin{array}{l}\text { Empyema before prolonged chest tube } \\
\text { duration, no. (\%) }\end{array}$ & $13(20.6)$ & $10(29.4)$ & $3(10.3)$ & .11 \\
\hline $\begin{array}{l}\text { Empyema after prolonged chest tube } \\
\text { duration, no. }(\%)\end{array}$ & $8(12.7)$ & 7 (20.6) & $1(3.4)$ & .06 \\
\hline Hemothorax, no. $(\%)$ & $0(0)$ & $0(0)$ & $0(0)$ & \\
\hline $\begin{array}{l}* 63 \text { episodes in } 61 \text { subjects } \\
\mathrm{CT}=\text { computed tomography } \\
\mathrm{PIP}=\text { peak inspiratory pressure } \\
\dot{\mathrm{V}}_{\mathrm{E}}=\text { minute ventilation } \\
\mathrm{V}_{\mathrm{T}}=\text { tidal volume }\end{array}$ & & & & \\
\hline
\end{tabular}

one had empyema before pneumothorax, and 4 were transferred from the ICU to an ordinary ward against the advice of the attending physician). Among the 88 subjects enrolled, 51 subjects $(57.9 \%)$ with 52 episodes of pneumothorax successfully had their chest tubes removed, and the median chest tube duration was 18 days (range 2-88 d). Twenty-seven subjects who died with chest tubes before the median chest tube duration (18 d) were excluded. Thus, in total, 61 subjects and 63 episodes of pneumothorax were analyzed and divided into a prolonged chest tube duration group ( $>18 \mathrm{~d}$ ) and a non-prolonged group ( $\leq 18 \mathrm{~d}$ ). There were 34 subjects with 34 events in the prolonged chest tube duration group, and 29 subjects with 29 events in the non-prolonged group. The baseline characteristics of the study subjects are shown in Table 1, and there were no significant differences between the 2 groups.

\section{Impact of Prolonged Chest Tube Duration on Outcomes}

The outcomes of the study subjects are shown in Table 2. The subjects with prolonged chest tube duration had longer ICU stay $(34.0 \pm 17.7 \mathrm{~d}$ vs $20.2 \pm 9.1 \mathrm{~d}, P=.001)$, hospital stay $(62.7 \pm 44.8 \mathrm{~d}$ vs $34.6 \pm 21.7 \mathrm{~d}, P=.004)$, and mechanical ventilation after development of pneumothorax $(35.4 \pm 32.3 \mathrm{~d}$ vs $15.2 \pm 13.5 \mathrm{~d}, P=.003)$, and higher ICU mortality $(38.2 \%$ vs $6.9 \%, P=.006)$ and hospital mortality $(50.0 \%$ vs $24.1 \%, P=.04)$.

\section{Factors Associated With Prolonged Chest Tube Duration}

The initial manifestations of pneumothorax in the study subjects are shown in Table 3. Prolonged chest tube duration was significantly associated with a higher rate of 
Table 4. Logistic Regression Analysis of Factors Associated With Prolonged Chest Tube Duration

\begin{tabular}{|c|c|c|c|c|}
\hline & $\begin{array}{c}\text { Univariate } \\
\text { Odds Ratio }(95 \% \mathrm{CI})\end{array}$ & $P$ & $\begin{array}{l}\text { Multivariate Adjusted } \\
\text { Odds Ratio }(95 \% \mathrm{CI})\end{array}$ & $P$ \\
\hline Age & $0.98(0.93-1.02)$ & .31 & $0.92(0.83-1.01)$ & .08 \\
\hline Sex & $1.19(0.22-6.42)$ & .84 & $2.33(0.09-57.79)$ & 60 \\
\hline Smoking & $2.57(0.92-7.18)$ & .07 & $1.06(0.21-5.41)$ & .94 \\
\hline Acute Physiology and Chronic Health Evaluation II score & $1.03(0.95-1.12)$ & .45 & $1.07(0.94-1.21)$ & .31 \\
\hline $\mathrm{P}_{\mathrm{aO}_{2}} / \mathrm{F}_{\mathrm{IO}_{2}}$ & $1.00(1.00-1.00)$ & .81 & $0.99(1.00-1.01)$ & .86 \\
\hline Procedure-related pneumothorax & $1.08(0.37-3.18)$ & .89 & & \\
\hline Bilateral pneumothorax & $3.73(0.39-35.46)$ & .25 & & \\
\hline Concurrent septic shock & $1.31(0.20-8.41)$ & .78 & & \\
\hline Tension pneumothorax & $2.71(0.27-27.58)$ & .40 & & \\
\hline Maximum minute ventilation & $1.15(0.97-1.37)$ & .11 & $0.98(0.66-1.44)$ & .90 \\
\hline Maximum tidal volume & $1.00(0.99-1.00)$ & .86 & & \\
\hline Maximum PEEP & $1.04(0.85-1.26)$ & .72 & & \\
\hline Maximum breathing frequency & $1.08(0.98-1.18)$ & .11 & $1.13(0.92-1.38)$ & .25 \\
\hline Maximum peak inspiratory pressure & $1.13(1.02-1.26)$ & .03 & $1.18(1.01-1.37)$ & .03 \\
\hline $\begin{array}{l}\text { Surgical emphysema before prolonged chest tube } \\
\quad \text { duration }(n=38)\end{array}$ & $4.60(1.56-113.61)$ & .006 & $11.18(2.03-61.51)$ & .006 \\
\hline Empyema before prolonged chest tube duration $(n=13)$ & $3.61(0.89-14.71)$ & .07 & $2.54(0.33-19.70)$ & .37 \\
\hline
\end{tabular}

CT $(67.6 \%$ vs $37.9 \%, P=.02)$, a higher number of CTs $(1.2 \pm 1.2$ vs $0.4 \pm 0.6, P=.003)$, a higher number of chest tubes $(1.7 \pm 0.8$ vs $1.2 \pm 0.5, P=.005)$, a higher maximum PIP $\left(27.6 \pm 6.2 \mathrm{~cm} \mathrm{H}_{2} \mathrm{O}\right.$ vs $24.0 \pm 5.2 \mathrm{~cm} \mathrm{H}_{2} \mathrm{O}$, $P=.03)$, a higher rate of surgical emphysema (76.5\% vs $41.4 \%, P=.009$ ), and a trend toward more empyema after prolonged chest tube duration $(20.6 \%$ vs $3.4 \%$, $P=.06$ ). Additionally, in subjects with chest CT, subjects in the prolonged group ( 9 of 23 subjects, 39.1\%) had a trend toward a higher rate of chest tube malposition $(P=.07)$ than did the non-prolonged group (1 of 11 subjects, $9.1 \%$ ).

\section{Independent Risk Factors Associated With Prolonged Chest Tube Duration}

In the multivariate logistic regression analysis the significant predictors of prolonged chest tube duration were maximum PIP within 24 hours after insertion of chest tube (odds ratio $1.178,95 \% \mathrm{CI} 1.014-1.370, P=.03$ ) and surgical emphysema (odds ratio 11.182, 95\% CI 2.033$61.514, P=.006$ ) (Table 4). The receiver operating characteristic curve analysis revealed that the optimal cutoff point to create dichotomous variables for maximum PIP was $25 \mathrm{~cm} \mathrm{H}_{2} \mathrm{O}$ (sensitivity 0.72 , specificity 0.63 , area under the curve 0.70). Kaplan-Meier analysis of the rate of chest tube removal within 28 days after chest tube insertion (Fig. 2) indicated that the probability of chest tube removal was significantly lower and removal of the chest tube was also delayed when both surgical emphysema and a high PIP were present, compared with subjects without surgical emphysema or a high PIP (log-rank $P=.001)$.

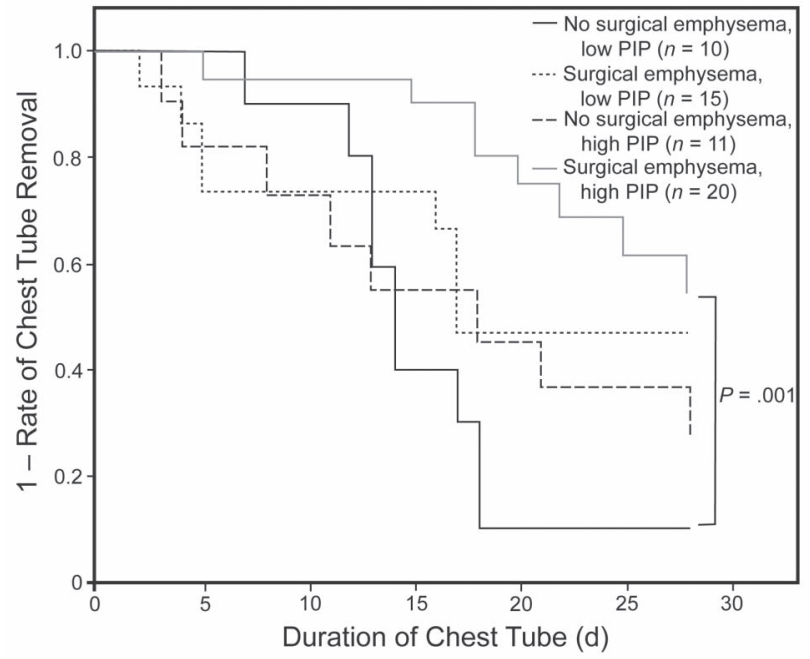

Fig. 2. Kaplan-Meier curve for chest tube duration in subjects who developed pneumothorax after initiation of mechanical ventilation. We divided the subjects into 4 groups, according to the presence/ absence of surgical emphysema, and peak inspiratory pressure (PIP) $>25 \mathrm{~cm} \mathrm{H}_{2} \mathrm{O}$ versus $\leq 25 \mathrm{~cm} \mathrm{H}_{2} \mathrm{O}$. The lowest percentage of chest tube removal within 28 days after thoracostomy was in the group with surgical emphysema and high PIP (log rank $P=.001$, compared with no surgical emphysema and low PIP).

\section{Discussion}

The importance of avoiding prolonged chest tube duration has been identified with other pleural diseases. ${ }^{18}$ However, little attention has been paid to chest tube duration in patients on mechanical ventilation, ${ }^{16,17,19}$ in whom management is more complicated ${ }^{17}$ and the impact of prolonged chest tube duration is unknown. 
Our subjects had an average age of 78 years, and various comorbidities, especially COPD. We found that prolonged chest tube duration after pneumothorax was associated with higher mortality, longer ICU and hospital stay, and longer mechanical ventilation after pneumothorax. The prolonged chest tube duration subjects also tended to receive more chest CTs, have more chest tubes, and have a higher rate of empyema. These findings indicate that the burden of critical care is increased in subjects with pneumothorax and prolonged chest tube duration. This seems an inviting topic to explore to shorten the period of thoracostomy.

Notably, in this retrospective study, we also found an association between prolonged chest tube duration and thoracostomy complications. Thoracostomy complications have a relatively high incidence $\left(\sim 25-30 \%^{8,9}\right)$ and may worsen outcomes..$^{3-9}$ Subcutaneous emphysema is usually thought to be only a cosmetic issue. ${ }^{16,20}$ Jones et al enrolled 134 subjects, and 17 (12.6\%) of them were mechanically ventilated. Subjects with subcutaneous emphysema after thoracostomy (so-called surgical emphysema) had a higher mortality rate, longer chest tube duration, and a higher incidence of chest tube malposition. ${ }^{6}$ However, in that study, a much higher percentage of subjects with surgical emphysema were mechanically ventilated, which may have biased the results. In our subjects, surgical emphysema was significantly associated with prolonged chest tube duration in subjects who developed pneumothorax during ventilation. That observation reinforces the viewpoint that surgical emphysema in mechanical ventilated patients is associated with prolonged chest tubes duration and may reflect inadequate functioning of the chest tube or chest tube malpositioning.

Interestingly, 34 of our subjects (55.7\%) received chest $\mathrm{CT}$ to evaluate pneumothorax. On average, they received their first CT at about 10.5 days after thoracostomy. We hypothesize that this may be too late to evaluate chest tube malfunctioning and pneumothorax-associated complications. Subjects with prolonged chest tube duration have a trend toward a higher rate of chest tube malposition, so we suggest early chest CT to avoid prolonged chest tube duration. We suggest CT instead of $\mathrm{X}$-ray, because $\mathrm{x}$-ray is less accurate for assessing pneumothorax or chest tube malpositioning..$^{21-24}$

In our results, prolonged chest tube duration was also associated with higher PIP. Positive pressure from a ventilator is believed to delay healing of pneumothorax, ${ }^{17}$ and a higher inspiratory pressure may worsen persistent air leak. However, the influence of ventilator settings on the resolution of pneumothorax and chest tube duration has not been investigated. We found that prolonged chest tube duration was significantly associated with a higher maximum PIP within 24 hours of thoracostomy. Fur- thermore, when we evaluated the impact of surgical emphysema and high PIP $\left(>25 \mathrm{~cm} \mathrm{H}_{2} \mathrm{O}\right)$ on chest tube removal, it was found that the rate of chest tube removal in subjects with both adverse factors was half that of subjects without either factor on day 28 after chest tube insertion (see Fig. 2).

Our study has some limitations. First, this was a retrospective study, and the ventilator setting records were not available for 7 subjects. Second, we focused on subjects who developed pneumothorax during mechanical ventilation. Whether our findings can be generalized to patients who develop pneumothorax without mechanical ventilation remains unknown. Third, our subjects were mainly elderly and had a high rate of COPD. The generalization of our findings to patient populations with other characteristics warrants further investigation. Fourth, because of the limitations of a retrospective study, there could be confounding factors we did not account for.

\section{Conclusions}

Prolonged chest tube duration was associated with a higher mortality, a longer duration of mechanical ventilation after development of pneumothorax, and longer ICU and hospital stay. Surgical emphysema and high PIP within 24 hours after thoracostomy were independent predictors of prolonged chest tube duration.

\section{ACKNOWLEDGMENTS}

We thank all the healthcare workers of the respiratory care unit in the Taipei Veterans General Hospital for their valuable contributions to patient care. We are also grateful to Ralph Kirby MD for his help with language editing.

\section{REFERENCES}

1. Yarmus L, Feller-Kopman D. Pneumothorax in the critically ill patient. Chest 2012;141(4):1098-1105.

2. Woodside KJ, vanSonnenberg E, Chon KS, Loran DB, Tocino IM, Zwischenberger JB. Pneumothorax in patients with acute respiratory distress syndrome: pathophysiology, detection, and treatment. J Intensive Care Med 2003;18(1):9-20.

3. Baumann MH. What size chest tube? What drainage system is ideal? And other chest tube management questions. Curr Opin Pulm Med 2003;9(4):276-281.

4. Shaikhrezai K, Zamvar V. Hazards of tube thoracostomy in patients on a ventilator. J Cardiothorac Surg 2011;6:39-40.

5. Harris A, O'Driscoll BR, Turkington PM. Survey of major complications of intercostal chest drain insertion in the UK. Postgrad Med J 2010;86(1012):68-72.

6. Jones PM, Hewer RD, Wolfenden HD, Thomas PS. Subcutaneous emphysema associated with chest tube drainage. Respirology 2001; 6(2):87-89.

7. Peek GJ, Firmin RK, Arsiwala S. Chest tube insertion in the ventilated patient. Injury 1995;26(6):425-426.

8. Bailey RC. Complications of tube thoracostomy in trauma. J Accid Emerg Med 2000;17(2):111-114. 


\section{Impact and Predictors of Prolonged Chest Tube Duration}

9. Chan L, Reilly KM, Henderson C, Kahn F, Salluzzo RF. Complication rates of tube thoracostomy. Am J Emerg Med 1997;15(4):368-370.

10. Light RW. Pleural controversy: optimal chest tube size for drainage. Respirology 2011;16(2):244-248.

11. Lin YC, Tu CY, Liang SJ, Chen HJ, Chen W, Hsia TC, et al. Pigtail catheter for the management of pneumothorax in mechanically ventilated patients. Am J Emerg Med 2010;28(4):466-471.

12. Tsai WK, Chen W, Lee JC, Cheng WE, Chen $\mathrm{CH}, \mathrm{Hsu}$ WH, et al. Pigtail catheters vs large-bore chest tubes for management of secondary spontaneous pneumothoraces in adults. Am J Emerg Med 2006;24(7):795-800.

13. Tawil I, Gonda JM, King RD, Marinaro JL, Crandall CS. Impact of positive pressure ventilation on thoracostomy tube removal. J Trauma 2010;68(4):818-821.

14. Bell RL, Ovadia P, Abdullah F, Spector S, Rabinovici R. Chest tube removal: end-inspiration or end-expiration? J Trauma 2001;50(4): 674-677.

15. Chen KY, Jerng JS, Liao WY, Ding LW, Kuo LC, Wang JY, et al. Pneumothorax in the ICU: patient outcomes and prognostic factors. Chest 2002;122(2):678-683.

16. Henry M, Arnold T, Harvey J; Pleural Diseases Group; Standards of Care Committee; British Thoracic Society. BTS guidelines for the management of spontaneous pneumothorax. Thorax 2003;58(Suppl 2):ii39-ii52.
17. Zimmerman JE, Dunbar BS, Klingenmaier CH. Management of subcutaneous emphysema, pneumomediastinum, and pneumothorax during respirator therapy. Crit Care Med 1975;3(2):69-73.

18. Ramanathan R, Wolfe LG, Duane TM. Initial suction evacuation of traumatic hemothoraces: a novel approach to decreasing chest tube duration and complications. Am Surg 2012;78(8):883-887.

19. Baumann MH, Strange C, Heffner JE, Light R, Kirby TJ, Klein J, et al. Management of spontaneous pneumothorax: an American College of Chest Physicians Delphi consensus statement. Chest 2001; 119(2):590-602.

20. Maunder RJ, Pierson DJ, Hudson LD. Subcutaneous and mediastinal emphysema. Pathophysiology, diagnosis, and management. Arch Intern Med 1984;144(7):1447-1453.

21. Tocino IM, Miller MH, Fairfax WR. Distribution of pneumothorax in the supine and semirecumbent critically ill adult. AJR Am J Roentgenol 1985;144(5):901-905.

22. Omar HR, Abdelmalak H, Mangar D, Rashad R, Helal E, Camporesi EM. Occult pneumothorax, revisited. J Trauma Manag Outcomes 2010;4:12-17

23. Cameron EW, Mirvis SE, Shanmuganathan K, White CS, Miller BH. Computed tomography of malpositioned thoracostomy drains: a pictorial essay. Clin Radiol 1997;52(3):187-193.

24. Gayer G, Rozenman J, Hoffmann C, Apter S, Simansky DA, Yellin A, et al. CT diagnosis of malpositioned chest tubes. Br J Radiol 2000;73(871):786-790. 